\title{
Política prisional e garantia de atenção integral à saúde da criança que coabita com mãe privada de liberdade, Moçambique
}

\begin{abstract}
Prison policy and guarantee of comprehensive care to the health of the child who lives together with mother deprived of freedom, Mozambique
\end{abstract}

Edgar Luís Arinde', Maria Helena Mendonça²
1 Direccão Provincial de Saúde de Niassa (DPS), Núcleo de Investigação Operacional de Niassa (Nion) - Niassa (Niassa), Moçambique. edarinde@yahoo.com.br

2 Fundação Oswaldo Cruz (Fiocruz), Escola Nacional de Saúde Pública Sergio Arouca (Ensp) - Rio de Janeiro (RJ), Brasil.
DOI: 10.1590/0103-1104201912003

RESUMO A provisão dos cuidados de saúde implica o princípio dos direitos fundamentais do homem, enfatizado por Moçambique, uma nação emergente, ao considerar a saúde como um bem para o desenvolvimento sustentável previsto na Constituição da República, e garantida de forma equânime. Contudo, observa-se o ingresso preocupante no sistema prisional de mulheres com crianças pequenas que carecem de garantia do acesso a cuidados de saúde especiais. O estudo teve como objetivo fundamental analisar e descrever de que maneira a política de atenção integral à saúde da criança dos 0-5 anos, estabelecida pelo Serviço Nacional de Saúde em Moçambique, está incorporada no Serviço de Cuidados Sanitários Penitenciários. A abordagem qualitativa incidiu sobre as mães de crianças pequenas que vivem no presídio de Ndlavela, tendo em conta as variáveis que descreveram as condições socioeconômicas, demográficas e as relativas às condições biológicas da mulher com crianças. Participaram do estudo, por meio de entrevistas, duas gestantes e cinco mães em coabitação com crianças. Os dados coletados foram tratados por meio da análise de conteúdo segundo Bardin. Essas mulheres são jovens, solteiras, com baixa escolaridade, sem suporte nutricional e de saúde adequados e foram abandonadas pelas suas famílias de origem ou de formação, as quais realizavam atividades domésticas e de comércio informal. Observou-se que esse grupo é duplamente vulnerável e socialmente marginalizado, por ser pouco favorecido pelas políticas públicas de saúde. Conclui-se que a política de saúde necessita ser desdobrada, voltar-se para a necessidade e a importância de uma atenção à saúde mais igualitária, adequada e resolutiva, independentemente da situação legal, razão por que sublinha-se que essa realidade ainda está distante do preconizado sobre a assistência sanitária nos estabelecimentos penitenciários.

PALAVRAS-CHAVE Atenção à saúde. Cuidado pré-natal. Gravidez. Prisões. Defesa da criança.

ABSTRACT The provision of health care implies the principle of fundamental human rights, emphasized by Mozambique, an emerging nation, when considering health as a good for the sustainable development provided for the Constitution of the Republic, and assured in an equitable manner. However, there is a worrying entrance into the prison system of women with young children who lack access guarantee and special health care. The main objective of this study was to analyze and describe how the comprehensive health care policy for children aged 0-5 years, established by the 
National Health Service in Mozambique, is incorporated into the Prison Health Care Service. The qualitative approach focused on mothers with small children residing in the Ndlavela prison, taking into account the variables that only described the socioeconomic, demographic conditions and the ones related to biological conditions of women with children. Two pregnant women and five mothers in cohabitation with children participated in the study, through interviews. The data collected were treated by the Bardin content analysis. These women are young, single, low schooling, without adequate nutritional and health support and were abandoned by their families of origin or formed, and who were engaged in domestic activities and informal trade activities. It was observed that this group is doubly vulnerable and socially marginalized, because it is not favored by public health policies. It is concluded that the health policy needs to be unfolded, turning to the need and importance of a more egalitarian, adequate and resolutive health care, regardless of the legal situation, which is why it is emphasized that this reality is still far from the one recommended for health care in prisons.

KEYWORDS Health care. Prenatal care. Pregnancy. Prisons. Child advocacy.

\section{Introdução}

Nas últimas décadas, a privação de liberdade está ganhando contornos dramáticos ao registar um crescimento rápido e implacável da população prisional em países como China (1,6 milhão), EUA (2,2 milhões), Rússia (674 mil) e Brasil (607 mil), que possuem os maiores números de encarcerados em âmbito planetário ${ }^{\mathbf{1}, 2}$.

Moçambique apresenta uma população jovem e representada, na sua maioria, pela camada feminina, com cerca de 12.614 .000 habitantes, em relação a 11.752 .000 da população masculina, perfazendo um total de 24.366.000 habitantes. $\mathrm{O}$ informe referente ao ano 2015 da Procuradoria-Geral da República de Moçambique e o Instituto Nacional de Estatística $^{3}$ denotam que, do universo populacional em Moçambique, 15.203 pessoas correspondem à população privada de liberdade em diversos estabelecimentos penitenciários do país, sendo que, dos 9.882 (60.0\%) condenados a penas de prisão efetiva, 5.321 (40.0\%) se encontram em prisão preventiva; dessa população presidiária, 80.0\% são jovens com menos de 35 anos de idade.
No entanto, a permanência de crianças que coabitam com as mães privadas de liberdade nas instalações para a execução penal é fato social que afeta a vida psicológica dos internados inocentes de forma permanente e contundente, suscitando na família uma reflexão sobre a estrutura da convivência familiar, na qualidade de guardiã da criança, e no Estado, sobre como garantir a legalidade e a responsabilidade dos estabelecimentos penitenciários por evitar o processo de mortificação da identidade da criança ${ }^{4}$.

A humanização das condições de encarceramento, o uso de modelos e políticas internacionalmente estabelecidos e acordados sobre os serviços correcionais, de saúde, de educação e de assistência social dentro do sistema prisional apoiam-se em fundamentos universais, dos quais Moçambique é signatário.

A política prisional de Moçambique sustenta que as crianças que coabitam com as suas mães reclusas recebem atenção à saúde adequada ao seu estado no estabelecimento prisional, sem explicitar a forma como a criança deve introduzir-se no meio social em igualdade com as demais crianças livres e o período que 
a criança menor de idade será cuidada e permanecerá com a mãe, durante o cumprimento da pena juridicamente instituída 5 .

Assim, avança-se, através do presente estudo, em uma perspectiva sociossanitária, com a descrição do grau de prestação de cuidados de saúde primários a crianças entre 0 a 5 anos de idade que coabitam com a mãe apenada no presídio de Ndlavela. A preocupação é preencher o vazio de informações e de conhecimentos que tratam da organização dos serviços de saúde, do acesso a cuidados de saúde e das condições de exercício da medicina no Serviço Nacional Penitenciário (Sernap), em Moçambique.

\section{Contexto de implementação dos cuidados de saúde da criança nos estabelecimentos penitenciários em Moçambique}

A Constituição da República de Moçambique define a dignidade da pessoa humana como um elemento essencial da expansão da liberdade, valor intrínseco e subjacente à condição humana. Os direitos humanos das pessoas privadas de liberdade não podem ser esquecidos nem negligenciados, para resguardar a sociedade de ações criminosas, que desrespeitam os princípios da convivência social, e para promover a construção de uma vida societária responsável e saudável de longo prazo ${ }^{6}$.

O governo de Moçambique, por meio do Ministério de Saúde, organizou políticas públicas intersetoriais e integrativas para melhorar os níveis de vida e de saúde da população moçambicana, estabelecendo quatro níveis de organização dos cuidados em saúde com vistas a prevenir, tratar e estabelecer ações para promoção da saúde, consoante com o posicionamento da Organização Mundial da Saúde (OMS) ${ }^{7}$.

As unidades de saúde dos estabelecimentos penitenciários pertencem ao primeiro nível de atenção à saúde e se articulam por referenciamento e contrarreferenciamento com hospitais dos níveis subsequentes, localizados nas áreas geográficas a elas circunscritas. Em face da vulnerabilidade e do desencadeamento de doenças entre a população prisional, torna-se inadiável a integração dos estabelecimentos penitenciários aos serviços de saúde local, condizente com a promoção de atenção integral a toda população confinada, em especial, as crianças que vivem com as mães.

A função essencial dos cuidados primários, quando integrados às ações de saúde pública, é ampliar intervenções de saúde pública nacionais para que as comunidades sejam mais saudáveis. Sistemas de saúde contribuem para a equidade em saúde, justiça social e o fim da exclusão, se direcionados ao acesso universal e à proteção social ${ }^{8}$.

A disponibilidade dos serviços de diagnóstico e terapêuticos pode facilitar ou dificultar o acesso e o uso dos serviços de saúde dos grupos de populações socialmente menos privilegiados por estarem fortemente associados aos padrões de desigualdades sociais existentes na mesma comunidade e à sua distribuição geográfica ${ }^{9}$. Essas dimensões condicionantes do acesso e da utilização dos serviços de saúde têm expressões na presença física desses serviços e na disponibilidade de recursos humanos qualificados, representando condição necessária à garantia de atenção integral à saúde.

O Serviço de Cuidado Sanitário das Penitenciárias (SCSP), criado em 2013, é um órgão do Sernap, responsável pela saúde física, psíquica e social, com ênfase na prevenção, no tratamento e na reabilitação dos detidos preventivamente e condenados, e o Estabelecimento Penitenciário Especial para Mulheres (Epem) de Ndlavela faz parte dele. A atenção à saúde e ao bem-estar da mãe e da criança no estabelecimento prisional com cuidados pré-natais, do puérpero e da criança de 0 a 5 anos, privados de liberdade, são fatores importantes no processo de reeducação e na reintegração social da mulher.

As informações oficiais ilustram que o Epem 
de Ndlavela abrigava, até ao final do período da recolha de dados, 125 mulheres, distribuídas em 8 celas com 20 mulheres. As celas menos lotadas estavam destinadas às mulheres grávidas ou com crianças menores de cinco anos de vida, em sua maioria, provenientes da região Sul de Moçambique ${ }^{\mathbf{1 0}}$.

O estudo objetiva conhecer de que maneira a política de atenção integral à saúde da criança, estabelecida pelo Serviço Nacional de Saúde em Moçambique, traduz-se e está incorporada ao Serviço de Cuidados Sanitários Penitenciários, onde se enquadra o Posto de Saúde em funcionamento no Estabelecimento Penitenciário Especial para Mulheres de Ndlavela.

Todavia, o estudo tem como questão central investigar se os cuidados de saúde ofertados à criança que coabita com a sua mãe privada de liberdade são capazes de assegurar o acesso ampliado e universal à assistência curativa, preventiva e nutricional de forma adequada, preservando a responsabilidade criminal que recai sobre as mães e as políticas voltadas para a sua ressocialização e reintegração social.

\section{Metodologia}

O estudo descritivo transversal com abordagem qualitativa foi realizado no Epem de Ndlavela, localizado no município de Matola, província de Maputo, em Moçambique, e incidiu sobre a população de mulheres reclusas com crianças dos 0-5 anos de vida internadas no estabelecimento de execução penal feminino, através da amostragem não probabilística acidental"1 , durante o II Semestre de 2016. Foram realizadas entrevistas semiestruturadas com as mães das crianças e observação direta junto às estruturas de atenção após anuência da Direção Geral do Serviço Nacional Penitenciário, por parecer favorável do Comitê Institucional de Bioética para Saúde - Instituto Nacional de Saúde, sob registro 008/ CIBS-INS/2016, e da devida aprovação do Comitê Nacional de Bioética para Saúde do Ministério da Saúde, sob registro número 33/CNBS/2016 e referência 221/CNBS/2016.
Assim, todas as mães foram previamente informadas sobre o objetivo do estudo e, ao aceitarem participar, assinaram o termo específico que garante o anonimato e a sua confidencialidade. As entrevistas das participantes não foram gravadas, como inicialmente previsto, devido às normas vigentes no estabelecimento penitenciário. Foram, no entanto, redigidas no respectivo instrumento de recolha de dados e, em seguida, digitalizadas no programa informático Qualitative Data Analysis Software (WebQDA), versão II, criado em 2010, na República Portuguesa.

Os dados foram trabalhados com a técnica de análise de conteúdo proposta por Bardin 12, que compreende uma pré-análise das narrações contidas nas entrevistas devidamente transcritas e lidas de forma flutuante, com a finalidade de saber como é que as mulheres grávidas e mães com crianças de $0-5$ anos de vida receberam a atenção à saúde e o atendimento nutricional dentro do estabelecimento prisional. Ainda se levantaram outras formas de intervenção que apoiam o desenvolvimento integral da criança.

Posteriormente, a exploração do material se deu por meio de leituras detalhadas e meticulosas, das quais resultou a codificação do material, em função das decisões científicas previamente formuladas, que permitiu elaborar o quadro de referência que organizou os fragmentos de informação, facultando uma certa organização lógica, onde foram definidas categorias e subcategorias e a respectiva interpretação dos dados.

\section{Resultados e discussão}

Com base na matriz temática que explorou 'como é que as mulheres grávidas e mães com crianças de 0-5 anos de vida receberam a atenção à saúde e atendimento nutricional dentro do estabelecimento prisional, e demais formas de intervenção que apoiam o desenvolvimento integral da criança', este estudo inicialmente destaca a caracterização 
do grupo de participantes (quadro 1) e sistematiza uma categoria empírica - a presença de atenção especial à criança que vive com a mãe encarcerada e suas subcategorias sobre atendimento atempado, alimentação adequada e recreação das crianças (quadro 2).

\section{Caracterização sociodemográfica das participantes da pesquisa}

O estudo perscrutou sete mulheres, sendo que, destas, somente cinco eram mães que coabitam com crianças entre 0-5 anos. As demais eram gestantes. As mulheres são negras, com idade cronológica compreendidas entre 20-42 anos e mães de crianças com idades entre 1 e 4 anos, provenientes da zona periurbana (2) e rural (5) da região Sul da República de Moçambique, destacando-se a Província de Maputo. A maior parte professava a religião cristã protestante (5).

A maioria das entrevistadas afirmou ser solteira, com baixo nível de escolaridade e apresentava como ocupação profissional emprego doméstico e em restaurante ou trabalho no campo, antes do cumprimento das penas em regime fechado naquele estabelecimento penitenciário.

Quadro1. Perfil sociodemográfico das mulheres grávidas e das mães com crianças dos 0-5 anos de idade privadas de liberdade na penitenciária de Ndlavela, Moçambique

\begin{tabular}{clllllll}
\hline P & Instrução & Raça & E. Civil & Proveniência & Ocupação & Idade & Religião \\
\hline P01 & Médio & Negra & Solteira & Periurbana & Desempregada & 20 Anos & Protestante \\
P02 & Elementar & Negra & Solteira & Periurbana & Emp. Doméstica & 22 Anos & Protestante \\
P03 & Sem nível & Negra & Solteira & Rural & Desempregada & 42 Anos & Protestante \\
P04 & Sem nível & Negra & Solteira & Rural & Emp. Doméstica & 28 Anos & Protestante \\
P05 & Elementar & Negra & Solteira & Rural & Emp. Restaurante & 25 Anos & Católica \\
P06 & Elementar & Negra & Solteira & Rural & Emp. Restaurante & 37 Anos & Católica \\
P07 & Sem nível & Negra & Solteira & Rural & Emp. Doméstica & 28 Anos & Protestante \\
\hline
\end{tabular}

Fonte: Arinde $\mathrm{EL}^{\mathbf{2 2}}$.

Os achados assemelham-se aos documentados $^{\mathbf{1 3}}$ em estudo que traçou o perfil internacional dos prisioneiros do continente africano, identificando o perfil da população prisional feminina - maioria de jovens solteiras com filhos, baixo nível de escolaridade e renda familiar precária. Em Moçambique, os empregos domésticos e em restaurantes mencionados são atividades informais pouco remuneradas e carentes de uma legislação protecionista robusta.

Assim, as mães reclusas nessas condições de coabitação veem-se obrigadas a aceitar o que for estabelecido como o melhor e a confiar em quem lhe presta assistência, embora possa se sentir desamparada.

\section{Ação das agentes penitenciárias em face das solicitações das presidiárias em condição anormal no cárcere}

As entrevistadas relatam que, perante as dificuldades decorrentes das fragilidades físicas súbitas e com sinais de gravidade, são pontualmente atendidas pelas profissionais de segurança, conferindo-lhes apoio para diminuir problemas de saúde física e bem-estar para si 
ou para as crianças, estabelecendo elos afetivos entre elas e a segurança, o que favorece o reconhecimento da dignidade humana pelas profissionais.

Desde que estou grávida, passei mal de saúde duas vezes. No primeiro dia, foi durante a noite que comecei a sentir dores por baixo da barriga. As minhas amigas bateram o portão da cela com muita força a chamar os chefes que geralmente ficam por perto, daí o carro Isuzu veio até a porta a levar-me até o hospital de Ndlavela e me disseram que estava com ameaça de aborto e devia repousar. (P02).

Assim, no estabelecimento penitenciário de Ndlavela, observa-se a efetivação da dignidade, em respeito aos princípios da universalidade e igualdade firmados e garantidos a todos os cidadãos moçambicanos ${ }^{\mathbf{1 4}}$.

Quadro 2. Matriz temática sobre a assistência à criança de 0-5 anos que coabita com mãe privada de liberdade no estabelecimento penitenciário especial para mulheres em Ndlavella, Moçambique

\begin{tabular}{ll}
\hline Categoria de Análise & Subcategoria de Análise \\
\hline Presença da atenção à saúde especial à criança que & Atendimento à criança da mulher reclusa \\
vive com a mãe encarcerada & Alimentação adequada para o crescimento saudável da criança \\
& Material lúdico e espaço para recreação das crianças \\
\hline
\end{tabular}

Fonte: Arinde EL 22

Contudo, nota-se, também, a fraca capacidade desses profissionais da Justiça no que tange à visão generalista sobre os cuidados de saúde imprevistos, e afere-se que priorizam questões de segurança em detrimento das respostas aos gritos das mulheres com crianças pela saúde e pelo bem-estar, conforme explica a participante do estudo:

Esse assunto de interação com os chefes, principalmente durante a noite, não é fácil, depende de cada pessoa que está a trabalhar nesse dia. Eles demoram muito para atender às nossas preocupações. Quando eles vêem que a coisa é séria, aí levam-te e metem-te no carro até ao hospital de Ndlavela. (P01).

A desqualificação das lamentações das presidiárias de Ndlavela sobre o seu estado de saúde e bem-estar, principalmente no período noturno, por parte dos profissionais de segurança penitenciária, centra-se na lógica de que as suas falas são pouco críveis. A demanda por alocação de pessoal de saúde de nível superior e técnico visa a garantir uma atenção à saúde de qualidade no âmbito local, integrada a serviços mais complexos, e diminuir a exclusão social em face das situações de vulnerabilidade nos estabelecimentos penitenciários ${ }^{\mathbf{1 5}}$.

Ressalta-se, na incapacidade de alocação imediata desses recursos, a importância de oferecer treinamento aos profissionais de segurança penitenciária para reconhecimento de sinais de gravidade de certas doenças e eventos, bem como técnicas de atenção imediata no local no período em que o Posto de Saúde se encontra encerrado.

\section{Atenção especial à saúde da criança que vive com a mãe encarcerada}

O esforço concentrado na atenção à saúde da população infantil vivendo no estabelecimento penitenciário estudado é percebido pela organização, assim como a prontidão no acolhimento e a oferta desses serviços, 
que contemplam desde o primeiro contato no Posto de Saúde do presídio até a atenção especializada dos casos mais graves, com internação nas unidades sanitárias de média e alta complexidade de atenção para evitar a mortalidade infantil.

Apuraram-se, junto às participantes do estudo, as responsabilidades do Posto de Saúde do Epem de Ndlavela quanto à proteção integral da criança e aos cuidados primários de saúde, conforme as tendências mundiais e a situação da privação da liberdade da mãe.

Quando se trata de crianças, não há nenhuma dificuldade. Atendem muito rapidamente, basta comunicar à chefe de saúde da cela, e ela fala com os chefes, e atendem mesmo se for à noite. Elas levam ao hospital do estado com o carro que temos aqui na cadeia. (P03).

O Posto de Saúde do Epem de Ndlavela funciona como a primeira porta de contato dos indivíduos em situação prisional com o Sistema Nacional de Saúde, levando a atenção à saúde o mais próximo possível do local onde as pessoas vivem.

[...] Se você informar para eles que está se sentido mal ou a sua criança está com febre, ou mesmo que chegou o dia do peso, eles não têm demostrado resistência e nem problemas para cuidar da nossa saúde, apesar duma ou outra pessoa ter comportamento de agressividade... (P04).

Entretanto, as anotações de alguns dos casos nos gráficos de peso e crescimento não estavam sempre adequadas, e as orientações sobre a alimentação da criança não efetivadas no cartão de saúde. Assim, o presente estudo considera que a unidade sanitária do presídio, embora preocupada com a resolubilidade dos problemas de saúde das populações de maior vulnerabilidade mediante o atendimento e os cuidados imediatos, falha no acompanhamento e na preservação das condições de vida das crianças que ali vivem com suas mães.

\section{Alimentação oferecida às crianças pela instituição para o seu cresci- mento saudável}

Essas crianças sofrem as consequências diretas da falta de autonomia e limitação dos meios de subsistência das suas parentes em adquirir alimentos adequados e suficientes para o crescimento saudável, contribuindo para sua vulnerabilidade.

Falar de alimentação numa cadeia eu acho que é muito sensível... [risos] porque, se não fosse uma necessidade da vida, nos deixaria assim mesmo sem comer, por isso nos dão sempre feijão, peixe, xima, arroz... essa coisa de frutas ou sumo, eu nunca vi... e para mim, que estou grávida, é bastante preocupante. (P02).

As crianças que vivem aqui, quando vão para a creche, Ihes dão papas de farinha de milho, ou mesmo um pedacinho de pão ao mata-bicho; e no almoço, comem a mesma coisa que as mães comem... Mas, às vezes, não tem sido suficiente, porque quando voltam da creche, dizem: mãe, estou com fome, e aí é mesmo difícil, porque não temos onde recorrer para satisfazer as barrigas das nossas crianças... (P03).

Entende-se que se deveria desenvolver e adotar prioridades alimentares e nutricionais especiais para a população infantil para melhoria da atenção nutricional, promoção e proteção da saúde da criança.

Eu cheguei aqui quando a criança tinha 3 semanas e se alimentava somente de leite do peito, e deixou de mamar quando tinha 1 ano e 2 meses... é muito difícil, porque aos finais de semana e feriados a creche não abre, e quando a mãe recebe $1 / 2$ pão, deve se sacrificar e dar à criança para não passar fome... Outra coisa é que aqui não há comida especial para criança... tudo que a mãe come a criança é obrigada a comer [...]. (P04).

Certamente, nota-se que as mulheres presidiárias que coabitam com as suas crianças 
reconhecem a necessidade de privilegiar o aleitamento materno e de integrar outros alimentos, incluindo o leite artificial, mesmo sem recursos financeiros ou ajuda das familiares:

A única coisa especial que dão para as crianças é o leite lactogênio (3 latas por mês) [...] A minha criança chegou aqui quando estava a mamar e deixou quando tinha 1,3 anos [...] é muito difícil mesmo para as pessoas adultas comerem a mesma coisa todos os dias, refiro-me de: arroz, feijão, xima, peixe [...]. (P05).

$O$ perfil alimentar oferecido às crianças que vivem com as mães inclui cereais (arroz e farinha de milho), leguminosa (feijão), mariscos (peixe), leite artificial de fórmula infantil (Lactogênio), repartidos em duas refeições diárias: almoço e pequeno-almoço ${ }^{16}$. Incentivam-se as mães com crianças menores de 2 anos à prática e à continuação do aleitamento materno, recomendado pela OMS, mas sua efetivação é comprometida pela ausência de horários ou local dentro do presídio para que pratiquem tal atividade.

As propriedades nutricionais e imunológicas do leite materno protegem o recém-nascido de infeções gastrointestinais, respiratórias e urinárias, permitem o crescimento e o desenvolvimento saudável e fortalecem o vínculo mãe-filho, além de serem um fator de redução do índice de mortalidade infantil17,18.

\section{Desenvolvimento integral das crianças e atividades lúdicas e de recreação}

As mães do estudo consideraram a brincadeira infantil espontânea e livre, mesmo no ambiente carcerário, uma atividade social, prazerosa e fundamental para que as crianças sejam estimuladas cognitivamente, adquirindo conhecimentos sobre a realidade da vida, e desafiadas a realizar atividades corporais em diferentes planos. Essa interação entre elas e uma personalidade adulta no local tem o papel de supervisionar as brincadeiras e garantir o acesso e a utilização adequada dos brinquedos:

A escolinha daqui tem alguns brinquedos para as crianças quando querem se distrair, mas não podem levá-los para as celas ou mesmo para casa quando as mães tiverem solturas. Devem deixar aqui! ... todas nós temos conhecimento sobre isso... muitos brinquedos aqui existentes são oferecidos pelas organizações da sociedade civil quando vêm nos visitar. (P06).

Tem uma escolinha aqui dentro da cadeia para as crianças. Como pode ver, tem baloicos ali fora onde as crianças brincam. Mas esse ambiente não é adequado para as crianças se sentirem à vontade. Digo isso porque sou uma das titias que cuidava ao tempo inteiro dessas crianças, e elas mostram-se meio tímidas para brincarem. (P03).

A presença do ato de brincar e de se divertir, como um direito da criança, está garantida pelo Epem de Ndlavela por um espaço especial equipado com brinquedos recreativos. A hermenêutica da brincadeira deve ser encarada de forma séria e cautelosa, compreendida como relações e interações estabelecidas entre crianças usando ou não brinquedos no meio onde se insere. A reprodução de valores hegemônicos forja subjetividades, inicia princípios e mantém correspondências com a sociedade ${ }^{19}$.

As crianças têm um espaço para brincarem aqui dentro, que é na escolinha delas, mas, mesmo assim, as brincadeiras que elas fazem têm sido reflexo daquilo que têm visto no seu dia a dia aqui dentro. Chegam até a encenarem um encarceramento entre elas, e isso não é bom... (P05).

A brincadeira para reprodução e implementação ativa das situações vivenciadas corresponde à forma mais elevada da atividade intelectual na infância, aprendizagem fundamental que permite o surgimento da linguagem, do desenho, da imitação e da dramatização ${ }^{20}$. Nesse sentido, o comportamento dos meninos que coabitam com as mães em 
Ndlavela está de acordo com a literatura sobre o comportamento infantil. A atuação das mulheres, com papel de educadoras na creche, geralmente presidiárias bem-comportadas, é importante no desenvolvimento de brincadeiras e atividades que incidam sobre a construção da estrutura cognitiva positiva.

\section{Considerações finais}

Os muros da prisão não marcam apenas a ruptura do tempo e dos afetos que precisam ser ressignificados em outras dimensões estruturais e intervenções com intuito de alcançar condições humanas aceitáveis ${ }^{21}$. O estudo indica que a situação de encarceramento fragiliza as fontes de apoio familiar no que concerne à alimentação saudável, ao material de higiene e ao apoio socioafetivo das mulheres que convivem com as suas crianças nos espaços de execução penal.

Os propósitos do estudo foram alcançados satisfatoriamente, na medida em que se observaram os cuidados de saúde prestados no Posto de Saúde do Epem de Ndlavela, e conclui-se que transcendem a perspetiva biológica dessas mulheres, que coabitam com as suas crianças em tenra idade, e cumprem certa abordagem humanística voltada para a proteção da criança. A presença de marcas de atenção especial pode ser vista pelo acolhimento às demandas de ações de saúde; pelo incentivo às mães com crianças em idade de amamentação da prática e da continuação do aleitamento materno, mesmo que não estejam especificadas regras para a sua efetivação, pela oferta de alguns recursos de recreação e aprendizado cognitivo.

Contudo, não há uma percepção única da questão. Algumas mães não vêem o local como ambiente mais adequado para permanência com as suas crianças, mesmo que reconheçam a importância de sua presença como laço social nos primeiros anos de vida e como condição que se sobressai às demais circunstâncias vividas, como baixo apoio moral e afetivo de seus familiares. A análise ainda sublinha que tanto o Estado como a sociedade necessitam incrementar medidas legais previstas para a proteção integral e estabelecer mais diálogo com mulheres grávidas e mães com filhos de 0-5 anos encarceradas acerca das restrições impostas à socialização primária das crianças.

A realidade sociossanitária desse grupo duplamente vulnerável, socialmente marginalizado e pouco favorecido pelas políticas públicas de saúde e pela assistência ainda está distante do que é preconizado sobre a assistência sanitária nos estabelecimentos penitenciários. Ela indica a necessidade e a importância de seu desdobramento, com vistas a se alcançar uma atenção à saúde mais igualitária, adequada e resolutiva, independentemente da situação legal das mulheres-mães.

\section{Colaboradores}

Arinde EL (0000-0002-2103-4803)* e Mendonça MH (0000-0002-3917-9103)* contribuíram para a concepção do artigo, elaboração do rascunho, revisão crítica do conteúdo; e aprovação da versão final do manuscrito. 


\section{Referências}

1. Pavarini M. Cárcere e Fábrica: as origens do sistema penitenciário (Século XVI-XIX). Rio de Janeiro: Renavan; 2008. p. 68-76.

2. Brasil. Ministério da Justiça. [internet] [acesso em 2015 nov 3]. Disponível em: https://site-carlos. s3.amazonaws.com/uploads/redacao/apoio_1/213/ apoiol.pdf.

3. Moçambique. Informe anual do Procurador Geral da República à Assembleia da República. [Transmissão direta, Televisão de Moçambique] Maputo: tvm; 2016.

4. Goffman E. Manicômios, Prisões e Conventos [internet]. São Paulo: Perspectiva; 1974. [acesso em 2015 out 20]. Disponível em: http://www.observasmjc.uff.br/ psm/uploads/Manicomios-prisoes-e-conventos.pdf.

5. Moçambique. Serviço Nacional Penitenciário. Resolução do Conselho de Ministros no 65/2002 de 27 de agosto de 2002. Política prisional e estratégia da sua implementação para o desenvolvimento de um Sistema Prisional Unificado. Série I, número 34, 246(4) 2002.

6. Cabaco JLO. Moçambique: Identidades, Colonialismo e Libertação [tese]. [São Paulo]: Universidade de São Paulo; 2007. p. 475

7. Organização Mundial de Saúde. Atenção Primária em Saúde agora mais do que nunca, Relatório Mundial de Saúde. Lisboa: OMS; 2008.

8. Conceição MT, Figueiredo MC, Graça LC. Contributos de Intervenção de Enfermagem de Cuidados de Saúde Primária para a Promoção de Aleitamento Materno [internet]. Rev. Latino-Amer. 2011 [acesso em 2019 fev 25]. Disponível em: http://www.scielo. br/pdf/rlae/v19n2/pt_27.pdf.

9. Travassos C, Viacava F, Fernandes C, et al. Desigualdades Geográficas e Sociais na Utilização de Serviços de Saúde no Brasil. Ciênc. Saúde Colect. 2000; 5(1):133-149.
10. Instituto Nacional de Estatística (Moçambique). Mulheres e Homens em Moçambique. Indicadores Seleccionados de Gênero - 2011 [internet]. 2012 [acesso em 2015 maio 12] Disponível em: http://www.ine.gov. $\mathrm{mz} /$ estatisticas/publicacoes/mulheres-e-homens/ mulheres-e-homens.pdf/view.

11. Rudio FV. Introdução ao projeto de pesquisa. 31. ed. Petrópolis: Vozes; 2003.

12. Bardin L. Análise de conteúdo. Lisboa: Edições 70; 2009.

13. Walmsley R. Women and girls in penal institutions, including pre-trial detainees/remand prisoners. London: WPB/ICPR; 2013.

14. Vianna LW, Burgos MB, Salles PM. Dezessete anos de judicialização da política e das relações sociais no Brasil [internet]. Rev. de sociolog da USP. 1999 [acesso em 2016 nov 23]; 19(2):39-85. Disponível em http://www.scielo.br/pdf/ts/v19n2/a02v19n2. pdf.

15. Estivill J. Panorama da luta contra a exclusão social: Conceitos e estratégias. Genebra: Bureau International du Travail; 2003.

16. Santos IB. Empoderamento da grávida durante a vigilância da gravidez [dissertação]. [Viseu]: Escola Superior de Saúde Viseu; 2011. 178 p.

17. Levy L, Bértolo H. Manual de Aleitamento Materno [internet]. Portugual: Comitê Português para a UNICEF; 2012 [acesso em 2016 ago 11]. Disponível em: http://www.unicef.pt/docs/manual_aleitamento.pdf.

18. Paramasivam K, Michie C, Opara E, et al. Human breast milk immunology: a review. Int. j. fertil. women's med [internet]. 2006 [acesso em 2016 out 24]; 51(5):208-217. Disponível em: https://www. researchgate.net/publication/6534278_Human_ breast_milk_immunology_A_review. 
19. Brougère G. A criança e a cultura lúdica. In: Kishimoto TM. O brincar e suas teorias. São Paulo: Pioneira/Thomson Learning, 2002.

20. Piaget J. Intellectual Evolution from Adolescence to Adulthood. Human Development. 1972; 15(1):1-12.

21. Minayo MC, Constantino P. Deserdados Sociais: Condições de Vida e Saúde dos Presos do Estado do Rio de Janeiro: Fiocruz; 2015.

22. Arinde EL. Atenção à saúde à mulher e à criança dos $0-5$ anos de idade que coabitam com as mães priva- das de liberdade mo Estabelecimento Penitenciário Especial para Mulheres de Ndlavela em Maputo Moçambique [dissertação] [internet]. Rio de Janeiro: Fundação Oswaldo Cruz; 2017. 158 p. [acesso em 2019 fev 2]. Disponivel em: http://teses.icict.fiocruz. br/cgi-bin/wxis1660.exe/lildbi/iah/.

Recebido em 10/06/2018

Aprovado em 16/12/2018

Conflito de interesses: inexistente

Suporte financeiro: não houve 